\title{
Teatro, narcotráfico y violencia. Acerca del dRama Contrabando de Víctor Hugo Rascón Banda
}

\author{
José María Risso Nieva ${ }^{l}$ \\ Universidad Nacional de Tucumán (UNT) \\ Consejo Nacional de Investigaciones Científicas y Técnicas
}

(CONICET)

\begin{abstract}
Resumen: En el presente trabajo, estudiamos la obra teatral Contrabando (1991) del autor mexicano Víctor Hugo Rascón Banda, cuyo tema central es el fenómeno del narcotráfico. El comercio ilegal de estupefacientes inscribe a los personajes en un universo signado por la violencia y esta adquiere diversos grados de presencia. De acuerdo con ello, nos proponemos analizar en el drama el modo de representación de las acciones violentas asociadas al narcotráfico. Seguimos, principalmente, los postulados teóricos de Benjamin (Para una crítica de la violencia y otros ensayos) y Reguillo ("La narcomáquina"), sobre la violencia y el tráfico de drogas, respectivamente, y articulamos estos aportes con el modelo dramatológico, diseñado por José Luis García Barrientos (Cómo se comenta una obra de teatro), para el comentario de una obra teatral.
\end{abstract}

Palabras clave:Víctor Hugo Rascón Banda; drama; narcotráfico; violencia; grados de representación.

Recibido: 20 de febrero de 2019

Aprobado: 8 de abril de 2019

\section{THEATER, DRUG TRAFFICKING AND VIOLENCE. ABOUT THE DRAMA CONTRABANDO BY VÍCTOR HUGO RASCÓN BANDA}

Abstract: In the present work, we studied the play Contrabando (1991) by Mexican author Víctor Hugo Rascón Banda, whose central theme is the phenomenon of drug trafficking. The illegal trade of narcotics inscribes the characters in a universe marked by violence and this acquires varying degrees of presence. Accordingly, we analyze the mode of representation of the violent actions associated with drug trafficking in the drama. We follow, mainly, the theoretical postulates of Benjamin (Para una crítica de l violencia y otros ensayos) and Reguillo

\footnotetext{
${ }^{1}$ José María Risso Nieva es Licenciado en Letras. Se desempeña como Auxiliar Docente Graduado en la asignatura Lengua y Literatura Latinas I de la carrera Profesorado/Licenciatura en Letras, de la Universidad Nacional de Tucumán (UNT), provincia de Tucumán, Argentina.Correo electrónico: joma_153@hotmail.com
} 
("La narcomáquina"), on violence and drug trafficking, and articulate these contributions with the dramatological model, designed by José Luis García Barrientos (Cómo se comenta una obra de teatro), for the commentary of a play.

Keywords: Víctor Hugo Rascón Banda; drama; drug trafficking; violence; degrees of representation.

\section{Introducción}

Víctor Hugo Rascón Banda (1948-2008) es un autor teatral perteneciente a la generación de escritores llamada Nueva Dramaturgia Mexicana. Su producción dramática se caracteriza fundamentalmente por tratar los grandes problemas sociales de México de finales del siglo XX (Gann 87). En esta oportunidad, seleccionamos la obra de teatro Contrabando, cuyo tema central es el fenómeno del narcotráfico. La pieza, estrenada en 1991, constituye una transposición dramática de la novela homónima del autor, ganadora del Premio Juan Rulfo en dicho año.

En virtud del contenido, la obra puede inscribirse -junto con otras del autor, como por ejemplo, Guerrero Negro (1989)- en la tendencia estética definida por la crítica periodística y académica como "narcoteatro", que hace de la cultura, la violencia y la geografía del tráfico de drogas objeto de reflexión y tratamiento escénico (Moreno 144). En términos de Parra, escribir sobre el narco implica asumir la específica "situación histórica" que atraviesa México y revelar el entramado de ese contexto (p. 3).

En Contrabando, los personajes operan en un universo signado por la violencia y esta adquiere diversos grados de presencia. De acuerdo con ello, nos proponemos analizar en el drama el modo de representación de las acciones violentas asociadas al comercio ilegal de estupefacientes.

\section{Consideraciones teóricas}

Envirtud del objetivo propuesto, resulta oportuno definir las categorías teóricas básicas del análisis. En primer lugar, entendemos -desde una mirada general- el narcotráfico como el mercado ilegal de drogas, es decir, como un negocio ilícito dedicado a la comercialización de bienes prohibidos por la ley (Valdés Castellanos, Historia del narcotráfico). 
Se trata de un fenómeno complejo, entre cuyos componentes más conflictivos figura la violencia (Parra, p. 5). Ésta constituye un "medio" (Benjamin 23), implementado por distintos agentes y para diferentes fines: por un lado, es un instrumento de las mafias para la gestión del mercado de la droga (Reguillo, p. 3) y, por otro, es una de las vías del Estado, centrado en la "militarización", para combatir la actividad (p. 44). La violencia -en tanto objeto considerado- es una noción difícil de precisar puesto que admite diversas definiciones. La entendemos aquí como una acción intencional que, mediante el uso de la fuerza, provoca o puede provocar daños de distinta índole, contra uno mismo, otra persona, un grupo o una comunidad. En términos de Benjamin, este tipo de conducta destructiva constituye un "medio para fundar o modificar circunstancias" (28), es decir, transforma el equilibrio de un estado dado.

Bajo esta concepción, el análisis de la presencia de la violencia debe orientarse a la identificación de actos perniciosos. Siguiendo el modelo dramatológico para el comentario de una obra teatral, diseñado por García Barrientos, adoptamos la distinción de las acciones -según su grado de representación dramática- en patentes, latentes y ausentes $(2001,75)$. Llamamos patentes a las acciones "escenificadas", es decir, percibidas directamente por el público, y, por contraste, ausentes o "aludidas" a las que se sustraen a la captación del espectador. En un grado intermedio, se encuentran las denominadas latentes o "sugeridas" que -sin ser visibles- forman parte, junto con las patentes, de los sucesos representados en el transcurso de la obra. Entre las acciones latentes hay que encuadrar "las que preceden o siguen inmediatamente a las estrictamente escenificadas" (75) y aquellas que acontecen en los espacios contiguos, en tanto prolongaciones del espacio visible (135). La violencia, asociada al narcotráfico, debe entenderse en el marco de estas posibilidades de representación, según el modo dramático.

Finalmente, cabe señalar que nos aproximamos al estudio de Contrabando como "obra dramática", es decir, como "codificación literaria" de un drama (33). Este concepto refiere el objeto que leemos en forma de libro, integrando el correspondiente género literario y 
siendo, generalmente, anterior a la escenificación y, en alguna medida, independiente de ella.

\section{Una poética de la violencia}

La acción dramática principal de esta obra se construye a partir del encuentro de cuatro personajes (Conrada, Jacinta, Damiana y el escritor) que aguardan la llegada del presidente municipal, por un lapso de dos horas, en la oficina del funcionario, ubicada en Santa Rosa, un pueblo de la sierra de Chihuahua, México. Durante la espera, las figuras femeninas exponen una serie de experiencias relacionadas con narcotráfico. El protagonismo dado a la voz de la mujer y el hincapié puesto en el abordaje de la violencia constituyen rasgos constantes en la poética de Rascón Banda:

Algunos comentarios acerca de él ya se consideran, si no lugares comunes, sí de conocimiento general: que late en sus obras una violencia patente o latente, que se trata de un realismo ya poético, ya "verdadero"; que este dramaturgo se preocupa fundamentalmente por la situación de la mujer y de los oprimidos de su sociedad; y que maneja el lenguaje coloquial ágil y expertamente. (Gann 77)

El propósito de analizar en el drama la representación de acciones violentas, asociadas al narcotráfico, nos sitúa en el terreno de la poética o "poiesis teatral" (Dubatti, Introducción 128). Su abordaje implica determinar un "conjunto de constructos morfo-temáticos que, por procedimientos de selección y combinación, constituyen una estructura sígnica, generan un efecto, producen un sentido y portan una ideología estética en su práctica" (Dubatti, El teatro laberinto 13). Contrabando, en tanto ente individual o "micropoética" (Dubatti, Introducción 130), se vincula por semejanza con el conjunto de la producción o "macropoética" de Rascón Banda (Dubatti, Introducción 131). Como al respecto señala Navarrete Maya, ofreciendo una mirada general sobre el trabajo del autor, "la muerte y la violencia están presentes en casi todas sus obras, como el detonador de la acción, la culminación de ésta o su razón de ser" (95). 


\section{La violencia ausente: monólogos y corridos}

La representación de la violencia, en grado ausente, es decir, situada en la lejanía espacio-temporal y separada de los sucesos de la acción escenificada, constituye el modo privilegiado para el abordaje dramático del problema. Las acciones destructivas, relacionadas con el narcotráfico, son expuestas mediante a) la actualización de la función diegética de la dicción dramática y b) la construcción de relatos en forma de monólogos.

Siguiendo a García Barrientos, la función diegética o narrativa del discurso teatral "proporciona al público información que se sale del marco propiamente dramático, que pertenece al 'fuera de escena', en el espacio, en el tiempo o en cualquier aspecto de la percepción" (2001, 60). En el caso de Contrabando, la activación de este recurso permite a las mujeres del drama elaborar extensas narraciones, que asumen la modalidad del monólogo, en el marco del intercambio verbal. Podemos definir el monólogo teatral como un discurso "(de cierta extensión) sin respuesta verbal (considerable) del interlocutor, o porque no hay interlocutor o porque no puede o no quiere contestar verbalmente" (García Barrientos 2001, 64). En términos de Pavis, en esta modalidad, "el personaje se dirige a sí mismo" o "a un interlocutor que permanece mudo" (297). La obra que analizamos, en la construcción de los monólogos, se inclina por el segundo tipo de destinación: las mujeres, cada vez que asumen la palabra con el objeto de comunicar sus experiencias pasadas, inhiben la interacción y el resto de los personajes se limita a escuchar o a intervenir escuetamente.

En una obra teatral, la irrupción de discursos narrativos que articulan algún tipo de relato nos plantea un problema, puesto que dramaticidad y narratividad son dos modos distintos y opuestos de crear mundos ficcionales: "representación in-mediata (la actuación, el drama) frente a representación mediata (la narración)" (García Barrientos 2004, 513). El modo "in-mediato" determina tanto la escritura dramática como la representación teatral. De entrada, imprime en la obra dramática una estructura, radicalmente distinta a la del texto narrativo, fundada en diálogos y acotaciones. Por el contrario, el modo de representación de la narración se caracteriza por la mediación de la voz del narrador. Para 
que un elemento adquiera existencia narrativa "es necesario y suficiente que pase por la voz del narrador, que sea nombrado por él" (2004, 515516), mientras que, para ser dramatizado, debe entrar en el espacio y hacerse visible. Por esta razón, cuando nos interesamos por estos relatos de Contrabando, que irrumpen en el intercambio verbal, reflexionamos sobre hechos no visibles, es decir, exteriores a la acción dramática.

En el primero de ellos, Conrada narra la muerte de su hijo Candelo, en un sembradío de mariguana. En palabras de la madre, el joven ingresa al mundo del narcotráfico con el objetivo de mejorar la situación económica de la familia: “A todos nos va a ir muy bien, mamá, ya verá. Ya no tendrá que comer quelites ni andar pidiendo fiado" (Rascón Banda 20). La causa de la muerte es un disparo, pero en el relato coexisten varias versiones sobre el autor del suceso. La primera hipótesis señala como responsable del crimen a Astolfo, personaje en grado ausente, que emplea a Candelo para trabajar en un sembradío de mariguana (22). La segunda versión proviene del narcotraficante y asegura que la muerte es resultado de un accidente con el arma:

El Astolfo dice que él no lo mató ... Que el Candelo le pidió prestado el rifle 22 para matar un conejo ... y que como era un rifle viejo de su abuelo, al que había que golpear la cacha despacito, así, en una piedra, antes de dispararlo, para que se aflojara el tiro, que el Candelo le pegó muy fuerte en la laja y que el tiro se le fue al corazón (23).

Otro rumor, atribuido a un enunciador colectivo y difuso, originado en las dinámicas de la oralidad, señala que la muerte del joven es producto de una disputa territorial con otros traficantes de drogas:

Muchos dicen que no fue así. Que otros sembradores, enojados porque el Astolfo y el Candelo les habían ganado esa rinconada tan escondida, más allá de los Orates, lo venadearon desde la otra banda del río y amenazaron al Astolfo por si hablaba (23).

La última de las versiones barajadas responsabiliza a las fuerzas policiales de la muerte del joven: "le dispararon desde un helicóptero, porque la honda no parecía de 22. Era de bala expansiva" (23). 
En este relato, la acción violenta, en tanto conducta intencional y destructiva, identifica múltiples autores posibles: a) el propio Candelo, b) los narcotraficantes del propio bando o del contrario (Astolfo o los sembradores) y c) el Estado, a través de su aparato represivo. Como señala Parra, el tráfico de drogas es un "fenómeno integral, capaz de cimbrar - no destruir - todos los aspectos de la existencia humana, y también de sacar a relucir todas las miserias" (p. 5).

El segundo monólogo, a cargo de Jacinta, gira en torno al personaje de su marido, José Dolores Lima, y a la vinculación de este con el narcotráfico. La narración cuenta toda la historia de su relación, desde el encuentro, pasando por el casamiento y la vida conyugal, hasta la separación. Este desenlace está dado por la sorpresiva desaparición del hombre: "Fue la última vez que vi a José Dolores" (Rascón Banda 41). La unión con Lima conlleva para Jacinta una transformación radical de su estilo de vida y también el de su familia. Como señala al respecto Monsivais, el cambio definido por el "derroche" y la "ostentación" (34), constituye un rasgo de la cultura del narco:

José Dolores me puso casa en Hermosilla, amueblada de todo a todo, me compró una traca nuevecita, automática, y me enseñó a manejar para que yo hiciera mis compras. Me abrió una cuenta de inversiones y una cuenta de cheques en Bancomer. Qué días pasamos. Tan luego nos íbamos a Mazatlán, a una casa en la playa que tenía allá, con alberca y dos lanchas de motor, como a Tijuana, a una casa en el mejor fraccionamiento residencial, con un billar en el sótano. O nos íbamos a su rancho cerca de Nogales, con ganado fino, pasto artificial y casas para los peones. (Rascón Banda 35)

En este transcurrir, junto a José Dolores, no se registran actos de violencia. Esta aparece recién cuando el marido se fuga y se devela el origen de la prosperidad económica: el narcotráfico. La violencia se aplica sobre la familia de Jacinta, sospechada de complicidad, con las redes del tráfico de drogas. El sujeto de la acción es en este caso el militarismo estatal: "Maltrataron a mi familia y buscaron por toda la casa ... A mi papá, que les hizo frente, lo golpearon mucho y a mis hermanos también" (41). En este episodio los judiciales apelan a la agresión física como medio para combatir el narco. Dicha violencia 
deja marcas en los cuerpos de las víctimas: "mi papá ... desde entonces ya no puede caminar, porque lo dejaron como un Santo Cristo. Mis hermanos no tanto, aunque todavía les quedan las cicatrices" (42).

Por último, el monólogo que comporta mayores dosis de violencia es el de Damiana Caraveo. En su narración, la mujer da cuenta de un enfrentamiento acaecido en Yepachi, donde su familia es asesinada. Damiana inicia su relato a partir de la identificación de una acción violenta: una "balacera" (53), que la mujer ubica en el rancho, en donde están su marido (Rogelio Armenta) y sus hijos, junto a otros familiares del esposo. Este acto moviliza a Damiana a buscar auxilio en la policía de un pueblo lindante, Madroño. En compañía de estos llega a Yepachi y se ve inmersa en una embestida de la policía federal, frente a la cual los judiciales locales apenas pueden reaccionar. Sólo la mujer sobrevive y es sometida a interrogación y tortura. Luego es inculpada de pertenecer a una organización narco y encarcelada.

En relación con lo ocurrido en Yepachi, se ofrecen dos versiones: a) la oficial, emitida por la justicia federal, que construye una imagen triunfal del Estado sobre el comercio ilegal (una banda de narcotraficantes, junto con sus cómplices policiales, es aniquilada y la única sobreviviente es puesta en prisión) y b) la subjetiva, defendida por Damiana, quien sostiene su inocencia y la de su familia, atribuyendo la responsabilidad de la masacre a la complicidad de la administración estatal local, en particular al presidente municipal.

En los relatos de Damiana y Jacinta, e incluso en una de las versiones sobre la muerte del hijo de Conrada, el Estado se configura como actor de la violencia. Como al respecto señala Zavala, "no se trata de 'cárteles' que asedian la sierra sino de agentes federales y soldados del ejército que mantienen controles para toda la actividad vinculada al narco" (78).

Junto con los monólogos, en el transcurso de la obra, se intercalan cuatro narcocorridos. Éstos provienen del espacio latente y están a cargo de una banda de músicos, que nunca adquiere visibilidad. El corrido, como género musical, épico y político de principios del siglo $\mathrm{XX}$, exaltaba a célebres figuras históricas, como Zapata o Pancho Villa; el uso que se hace de este tipo de composición, en un contexto dominado por el narco, se organiza alrededor de la figura del traficante, 
destacando algunas hazañas de su vida y concluyendo con su muerte, que acontece siempre de modo violento. En Contrabando, por ejemplo, se nos informa acerca del suicidio de Ramiro o el accidente de Pedro e Inés, a través de las canciones tituladas "Hierba, polvo y plomo" (Rascón Banda 28-29) y "La camioneta gris" (49-50), respectivamente. Estos corridos se emparentan con las intervenciones del coro en la tragedia clásica griega, apropiándose principalmente de las "funciones narrativas al servicio de la acción" (Oliva y Torres Monreal 40), en tanto su contenido participa del desarrollo de los sucesos del drama. Los narcocorridos articulan otras historias, que se yuxtaponen a las vehiculadas por las mujeres a través de sus monólogos, y de esa forma amplían el abordaje del conflicto social, al mismo tiempo que multiplican las imágenes de representación de la violencia.

Asimismo, estos coros proporcionan claves para la interpretación del drama en su totalidad. Requieren, en virtud de lo señalado, especial atención los corridos titulados "Contrabando y traición" y "Ya encontraron a Camelia". El primero de ellos tiene como protagonistas a dos contrabandistas, Emilio Varela y Camelia la Texana, que consiguen pasar exitosamente un cargamento de mariguana de México a EE. UU. Tras la realización de la empresa, el varón decide abandonar a su compañera por otra mujer y, en función de esta afrenta, Camelia le da muerte y huye con el dinero de la venta: "Sonaron siete balazos,/Camelia a Emilio mataba" (Rascón Banda 15, las cursivas pertenecen al autor). Esta historia encuentra su continuación en el segundo corrido, que se intercala al final de la acción dramática, donde la mujer es acribillada por una banda de narcotraficantes que quieren apoderarse del dinero del contrabando: "Sonaron varios balazos/ Camelia cayó enseguida" (71, las cursivas pertenecen al autor). En esta historia, puede reconocerse que los actos violentos tienen distintos actores y estos a su vez están motivados por propósitos diferentes. Por un lado, Camelia actúa según un motivo personal (la venganza amorosa), mientras que la mafia apela al crimen en función de sus intereses económicos. El accionar de este clan se mantendría, en términos de Reguillo, dentro de los límites de "la violencia utilitaria, cuyos fines son legibles o aprehensibles para la experiencia (te mato para robarte, te aniquilo porque tu presencia estorba mis planes, etc., la muerte del otro es suficiente)" (p. 27). 
Ambos corridos unen los lexemas "traición" y "contrabando" y asocian el sintagma con un sentido trágico: "La traición y el contrabando terminan con muchas vidas" (71, las cursivas pertenecen al autor). Esta fórmula es asimilada por Damiana, en sus parlamentos finales, en un intento por dar sentido a su traumática experiencia personal y comprender el fenómeno del narco en la sierra. Para la mujer, el narcotráfico requiere de la complicidad del gobierno y el costo de este delito, que ella entiende como una afrenta al pueblo, está cuantificado en vidas humanas. Según Zavala, esta imagen visualiza "el poder del narco en el interior del poder del Estado" (78, las cursivas pertenecen al autor). De la instalación del comercio ilegal de mariguana en Santa Rosa y de la matanza de su familia y su encarcelación, Damiana culpabiliza al presidente municipal, a quien identifica como cultivador $y$, en función de su poder público, gestor de complicidades y silencios: “[El presidente] Fue a ver sus siembras de chutama, diría yo. Él está detrás de todo ... Todo se sabe, Conrada. Todo. Tú lo defiendes porque te tiene comprada con ese trabajo que te dio, después de lo de tu muchacho" (Rascón Banda 17).

\section{La violencia latente y visible}

En el plano de las acciones latentes, es decir, sugeridas que, sustrayéndose a la vista del espectador, acontecen en el espacio contiguo, se representa hacia el final la muerte del presidente municipal. Siguiendo las palabras de Jacinta, el episodio se sitúa en la cercanía del edificio en donde los personajes esperan la llegada del funcionario: "Hubo un encuentro en el retén del entronque. Mataron al presidente. Hay muchos muertos" (75). Se atribuye la responsabilidad de las muertes a un grupo en el que podría reconocerse la intervención de fuerzas del Estado, según la información brindada en una comunicación radial inmediatamente anterior a la enunciación del enfrentamiento:

VOZ MUJER: Afirmativo, Santa Rosa, afirmativo. Anota el radiograma para el presidente, el presidente. Urge mucho. Lo trajeron antier ... De parte de su hermano, de su hermano al presidente municipal. Que los soldados van para allá, para allá, cambio ... Por tierra y en helicópteros. Que salieron ya, salieron ya, adelante. (73-74) 
Sin embargo, esta información es insuficiente para reconocer la autoría de la muerte del presidente, manteniéndose entonces en la ambigüedad la identidad del grupo agresor.

Por su parte, la violencia visible tiene lugar en la escena final del drama. El grupo indefinido, en principio latente, que ha matado al presidente y viene bajando la loma, arrasa con el pueblo y entra en la oficina. Conrada y el escritor, que han permanecido en el lugar, mueren acribillados a balazos. La primera cae herida por un agresor situado en las cercanías, mientras que el poeta es asesinado por un hombre, que ingresa a la escena, haciéndose visible. Este nuevo personaje se mantiene en una completa indefinición, puesto que resulta imposible asignarle una pertenencia: "Podría ser un judicial o un narcotraficante vestido con ropa de la región" (78, las cursivas pertenecen al autor).

Como señala Harmony, la violencia "está en Contrabando, omnipresente, aunque con un pudor digno de los clásicos griegos se nos hace saber de ella - a excepción del final- sólo a través de los parlamentos-monólogos de las tres mujeres y de los coros" (9, las cursivas pertenecen al autor). En virtud de lo expuesto, tales acciones se representan fundamentalmente en grado ausente $\mathrm{y}$, con escasa frecuencia, de manera latente o patente. Esta predilección, además de responder a una necesidad escénica concreta (reducir el número de actores y preservar la integridad física de los mismos) y a una pretensión de "decoro" (evitar al público la exposición de escenas cruentas y sensibles), permite actualizar en el imaginario del espectador, o eventual lector, las experiencias particulares en torno al fenómeno del narcotráfico.

\section{En torno a la ambigüedad}

Es fundamental, en este tramo del análisis, abordar el problema de la ambigüedad como estrategia de configuración discursiva. En relación con el narcotráfico, la perspectiva cognitiva del drama, es decir, el grado de conocimiento que comparten los personajes y el público (García Barrientos, 2001, 220-221), se inclina por el "extrañamiento", dado que el espectador sabe menos que las personas del drama y siente la carencia de la información o advierte la ambigüedad en virtud de la provisión de datos confusos y contradictorios. 
Esta condición caracteriza los relatos de los personajes femeninos. Recuérdese, por ejemplo, las distintas versiones barajadas sobre la muerte de Candelo, que identifican distintos agresores. Ahora bien, sobre la madre de este se ciernen múltiples sospechas, promovidas fundamentalmente por el personaje de Damiana. Conrada se declara inocente de toda complicidad con las redes del narcotráfico; sin embargo, ha participado en la preparación del viaje del hijo y, luego de la muerte del joven, ha conseguido un puesto de radiotelegrafista, por obra del presidente municipal, acusado de contrabandista. En su relato prima el deseo de olvido más que de justicia: "Quiero olvidar lo que pasó" (Rascón Banda 20).

También en el caso de Damiana Caraveo hay una duplicación de las versiones sobre los episodios de violencia acaecidos: la oficial (hegemónica) y la personal (alternativa). La mujer se declara inocente de toda participación en el narco. Sin embargo, en la exposición de su relato, el escritor señala una serie de contradicciones, que restan credibilidad al alegato de la fémina:

ESCRITOR: ¿Por qué al Madroño, si eso está en otro municipio? (54)

ESCRITOR: ¿Es normal que su esposo se hubiera quedado a dormir en ese rancho?

DAMIANA: ¿Cómo? ¿Normal? El rancho también era de él, ¿no?

ESCRITOR: Sí, pero si él vivía en los Táscates, ¿por qué...? Bueno... déjelo. (59)

ESCRITOR: ¿Es normal que en un rancho haya tantas armas? (65)

En el caso de Jacinta, se esboza también cierta complicidad de la mujer con el narco. Aunque es su esposo José Dolores quien incurre en las prácticas del tráfico, encubierto como ganadero, Jacinta participa de la ostentación económica que le propone el marido. La mujer se refiere a las actividades del cónyuge de manera vaga e imprecisa, utilizando eufemismos del tipo "asuntos" o "negocios" (34). Jacinta no interroga sobre el origen de la riqueza, a pesar de tener noticias sobre la instalación de grupos ilegales en la zona fronteriza: 
Un día que vine a Santa Rosa me empezaron a contar de la mafia y todo, pero yo no creía nada. Sí, notaba que el pueblo ya no era el de antes. Como que se veía más movimiento, más gente forastera, más dinero, más progreso, usted sabe (35).

De cualquier forma, las mujeres, en el caso de tener algún tipo de complicidad en el tema, actúan de forma marginal en las redes del tráfico de drogas. El universo del contrabando diseñado en la obra es un mundo dominado por las figuras masculinas (Candelo, José Dolores, Rogelio Armenta), donde las mujeres asumen una posición auxiliar y restringida, de acuerdo con las funciones prescritas por el género: ser madre y esposa.

Por último, en torno al problema de la ambigüedad en Contrabando, es fundamental abordar el papel del escritor, cuya configuración se inclina decididamente por el extrañamiento, puesto que la información que puede obtener el espectador (o lector) sobre él es prácticamente nula. En contraposición con el predominio de la palabra femenina, en la obra, este personaje no tiene monólogo a cargo y su diálogo se limita a responder, escuetamente, a las interrogaciones de las mujeres.

En la construcción de este personaje podemos reconocer la inclusión de una serie de elementos autobiográficos. Es llamado con uno de los apellidos del autor, "Banda" (74), y se dedica -según declara- a la literatura como profesión: "Soy escritor" (47). Asimismo, al igual que el dramaturgo, ha nacido en Santa Rosa-Chihuahua-México, y ha emigrado a la capital del país para desarrollar su oficio:

DAMIANA: ... ¿De dónde vienes?

ESCRITOR: De México.

DAMIANA: ¿Y qué se te perdió por acá? ...

CONRADA: Es el hijo de Pimenio.

DAMIANA: (Al Escritor.) ¿Eres el grande o el chico?

ESCRITOR: El de enmedio.

DAMIANA: ... Te fuiste muy chico. (16)

Sin embargo, como sostiene Harmony: "la contradicción entre sus palabras y sus acciones le confiere una ambigüedad que lo descalifica como portavoz del dramaturgo" (8, las cursivas pertenecen al autor). 
En principio, su autopresentación como "poeta" resulta poco creíble, puesto que se basa en una imagen clisé del escritor, que define el arte como un modo de evasión social e iguala al artista con la divinidad:

ESCRITOR: ... los poetas crean sus propios universos. En un poema se puede explicar el verdadero sentido de la vida. Su misterio. ... Una cosa es la realidad y otra la creación literaria. La realidad sólo importa a quien la vive. La literatura ve más allá de los colores. Oye otras voces y sonidos. La poesía no cambia las cosas ni tumba autoridades. ... Los escritores tenemos otras preocupaciones ... Trascender la realidad. Encontrar el sentido exacto de las palabras y de la vida, ya le digo. Inventamos mundos y personajes. (Rascón Banda 48)

Sin embargo, esta imagen de sujeto despreocupado que intenta imponer, bajo el rótulo de "poeta", no coincide con su conducta. El acto de leer un libro, que sostiene durante gran parte del drama frente a las mujeres, pasa a representar una mueca, que en realidad encubre una actividad de espionaje: "Damiana y Conrada salen a la calle. El Escritor se levanta, se acerca al radio y lee rápidamente los radiogramas" (25, las cursivas pertenecen al autor). Asimismo, el personaje lleva un arma, cuya uso justifica en virtud de su afición a la caza: "El Escritor (...) [s] e descubre un costado y se saca del cinto una pistola 38 " (47, las cursivas pertenecen al autor). De acuerdo con lo expuesto, su identidad se va ubicando en una zona difusa, que oscila entre el narcotraficante y el policía:

DAMIANA: ¿Y tú eres narco?

ESCRITOR: (Pausa. La mira sorprendido.) ¿Cómo dice?

DAMIANA: Sí. Narco.

ESCRITOR: (Sonríe forzadamente.) No.

DAMIANA: Es que miras muy raro.

ESCRITOR: Así veo yo. La vista es muy natural.

DAMIANA: También te veo facha de judicial.

ESCRITOR: ¿También por la vista?

DAMIANA: Por la pistola. (47)

Hacia el final, se revela la impostura del poeta y se confirma su misión de espía. El escritor salva a punta de pistola la documentación 
oficial que las empleadas pretenden hacer desaparecer de la presidencia municipal. Sin embargo, no es posible, incluso en la instancia dramática del desenlace, definir su pertenencia a las redes del narco o a las fuerzas de seguridad. La figura se mantiene en la misma indeterminación que el hombre que le da muerte: "Podría ser un judicial o un narcotraficante" (78, las cursivas pertenecen al autor).

La ambigüedad observada en torno a la construcción de las personas del drama parece reproducir la presencia "fantasmagórica" de la organización narco (Reguillo, párr. 8), donde los agentes que sostienen el negocio se multiplican y las tramas de complicidades se diversifican, de forma -aparentemente- ilimitada. En este contexto, en donde no se sabe a ciencia cierta quién es quién, el fenómeno del narcotráfico se vuelve omnipresente, pudiendo abarcar bajo su dominio todas las esferas y sujetos.

\section{A modo de conclusión}

En Contrabando, Rascón Banda aborda uno de los grandes problemas sociales de México, el narcotráfico, y prioriza en el tratamiento del fenómeno uno de sus componentes más problemáticos: la violencia. Esta se representa en la obra fundamentalmente en grado ausente, a través de los monólogos y los corridos, que recuperan en la escena acontecimientos acaecidos en la distancia espacio-temporal, y en menor medida de forma latente o visible, como sucede hacia el final del drama.

Los personajes se construyen a partir del extrañamiento y sus figuras adquieren valores ambiguos en la trama de complicidades diseñada por la organización narco. En Contrabando los agentes del tráfico de drogas asumen una dimensión espectral, cerniéndose sobre la totalidad de las esferas humanas y configurándolas bajo el signo de la violencia.

\section{Referencias}

Benjamin, Walter. "Para una crítica de la violencia". Para una crítica de la violencia y otros ensayos. Madrid: Taurus, 1991. 23-45. Impreso.

Dubatti, Jorge. El teatro laberinto. Ensayos sobre teatro argentino. Buenos Aires: Atuel. 1999. Impreso.

Dubatti, Jorge. Introducción a los estudios teatrales. Buenos Aires: Atuel. 2012. Impreso. 
Moreno, Iani del Rosario. Theatre of the Borderlands. Conflict, Violence, and Healing. LanhamMD: Rowman \& Littlefield/Lexington Books. 2015. Google Libros. 21 Mar. 2019. Digital.

Gann, Mayra. "El teatro de Víctor Hugo Rascón Banda: Hiperrealismo y destino". Latin American Theatre Review. 1 Sep. 1991: 77-88. Latin American Theatre Review. 21 Mar. 2019. Digital.

García Barrientos, José Luis. Cómo se comenta una obra de teatro. Madrid: Síntesis. 2001. Impreso.

García Barrientos, José Luis. "Teatro y narratividad”. Arbor. 699-700 MarAbr. 2004: 509-524. Impreso.

Harmony, Olga. "Introducción”. Introducción. Rascón Banda, Víctor Hugo. Contrabando. México, D. F.: Ediciones El Milagro, 1993. 7-10. Impreso.

Monsiváis, Carlos. "El Narcotráfico y sus legiones". Viento rojo. Diez historias del narco. México D. F.: Plaza y Janés, 2004. 34-44. Impreso.

Navarrete Maya, Laura. "Rascón Banda, Víctor Hugo". Diccionario de escritores mexicanos - Siglo XX. Tomo VII. México: Universidad Nacional Autónoma de México, 2004. 94-107. Google Libros. 21 Mar. 2019. Digital.

Oliva, César y Torres Monreal, Francisco. Historia básica del arte escénico. Madrid: Cátedra. 1994. Impreso.

Parra, Eduardo Antonio. "Norte, narcotráfico y literatura". Letras Libres. Web. 12 Mar. 2019. https://www.letraslibres.com/mexico/norte-narcotrafico-yliteratura.Digital.

Pavis, Patrice. Diccionario del teatro. Barcelona: Paidós. 1998. Impreso.

Rascón Banda, Víctor Hugo. Contrabando. México, D. F.: Ediciones El Milagro. 1993. Impreso.

Reguillo, Rossana. "La narcomáquina y el trabajo de la violencia: apuntes para su decodificación". Hemispheric Institute. Web. 10 Oct. 2018. http:// hemisphericinstitute.org/es/emisferica-82/reguillo5.html/.Digital.

Valdés Castellanos, Guillermo. Historia del narcotráfico en México. México, D. F.: Aguilar. 2013. Impreso.

Zavala, Oswaldo. Los cárteles no existen: narcotráfico y cultura en México. Barcelona: Malpaso Ediciones SL. 2018. Lectulandia. 10 Oct. 2018.Digital. 